\title{
Transportes públicos e representações sobre mobilidade social: possíveis percepções a partir do Rio de Janeiro e de Buenos Aires
}

Public transportation and representations of social mobility: possible

perceptions from Rio de Janeiro and Buenos Aires

\section{Lênin Pires}

\section{(2) OpenEdition Journals}

\section{Edição electrónica}

URL: http://journals.openedition.org/aa/605

DOI: 10.4000/aa.605

ISSN: 2357-738X

\section{Editora}

Programa de Pós-Graduação em Antropologia Social (UnB)

\section{Edição impressa}

Data de publição: 31 dezembro 2013

Paginação: 165-193

ISSN: 0102-4302

\section{Refêrencia eletrónica}

Lênin Pires, «Transportes públicos e representações sobre mobilidade social: possíveis percepções a partir do Rio de Janeiro e de Buenos Aires», Anuário Antropológico [Online], v.38 n.2 | 2013, posto online no dia 01 fevereiro 2014, consultado o 28 abril 2021. URL: http://journals.openedition.org/aa/605 ; DOI: https://doi.org/10.4000/aa.605

Este documento foi criado de forma automática no dia 28 abril 2021.

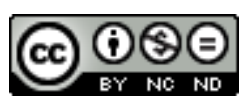

Anuário Antropológico is licensed under a Creative Commons Atribuição-Uso Não-Comercial-Proibição de realização de Obras Derivadas 4.0 International. 


\title{
Transportes públicos e
} representações sobre mobilidade social: possíveis percepções a partir do Rio de Janeiro e de Buenos Aires

\author{
Public transportation and representations of social mobility: possible \\ perceptions from Rio de Janeiro and Buenos Aires
}

Lênin Pires

\section{NOTA DO EDITOR}

Recebido em 16/07/2013

Aceito em 30/09/2013

\section{Introdução}

1 Neste artigo proponho uma reflexão sobre possíveis percepções a respeito da utilização de transportes públicos e representações de cidadania. E o faço a partir de etnografias realizadas em duas regiões metropolitanas distintas: Rio de Janeiro e Buenos Aires. Para este exercício, considerarei alguns processos nos quais, tendo em vista os contrastes suscitados, algumas representações me pareceram ser veiculadas. Ao utilizarem os serviços de transportes, os sujeitos, em uma dada sociedade, aparentam relacionar as dimensões de espaço e tempo, construindo e/ou conjugando formas específicas de classificação dos espaços sociais compartilhados. Ancoradas em arranjos sociais específicos, suas compreensões contextuais podem rebater em um enquadramento sensível, ensejando experiências políticas particulares. São vivências nas quais tais dimensões tendem a se configurar enquanto noções sobre liberdade e equidade. 
Embora a afirmação acima possa ser tomada como um truísmo, ela costuma aludir a contextos que dificilmente são descritos e analisados etnograficamente.

2 Minha abordagem buscará utilizar os dados construídos em etnografia realizada principalmente na Região Metropolitana de Buenos Aires, na Argentina. Minha narrativa recorrerá a dados igualmente construídos em etnografias sobre os trens urbanos no Rio de Janeiro, assim como à memória de outras experiências vivenciadas a partir do sistema de transporte público nesta última Região Metropolitana. Minha proposta não é necessariamente fazer uma comparação, mas realizar alguns contrapontos entre alguns destes dados, o suficiente para que eu busque interagir com as questões que propus e, por fim, sugerir alguns pontos à guisa de interpretação sobre as relações entre cidade, conflitos e direito.

\section{Cidade e Região Metropolitana}

O plano em que minhas observações se deram no Rio de Janeiro e Buenos Aires - a Região Metropolitana - abrigam fenômenos que me estimularam a introduzir um questionamento à sua representação política enquanto "agrupamento de municípios limítrofes, para integrar a organização, o planejamento e a execução de funções públicas de interesse comum". ${ }^{1}$ Afinal, de acordo com minha percepção, os limites da Região Metropolitana - definidos com base em negociações políticas que privilegiam a divisão física de territórios, a partir dos conflitos existentes entre elites mandatárias regionalizadas - não guardam necessariamente correspondência com as experiências sensíveis dos atores sociais e suas expectativas de mudanças na e da sociedade

Pode ser estimulante considerar a proposta de Castells $(1983,2010)$, para quem as cidades contemporâneas se caracterizam por uma reconfiguração espacial, constituída por redes globais que conectam tanto as regiões metropolitanas mais importantes quanto suas zonas de influência. Para este autor, o fator determinante de tais conexões são as tecnologias de comunicação e informação, fundamentadas na microeletrônica. Estas têm um papel fundamental no que Castells concebe como a maior onda de urbanização da história, fazendo surgir a característica fundamental das cidades contemporâneas: a Região Metropolitana. Nela, as infraestruturas de comunicação digital e de transportes constituem o sistema nervoso que Pain e Hall (2006) denominaram de megalópoles policêntricas.

Meu ponto de vista, porém, é que o processo de formação dessas áreas metropolitanas a cidade, por excelência - está centrado nos indivíduos "de carne e sangue" e nas suas performances de socialização. Neste sentido, sem desconsiderar as tecnologias de comunicação, são decisivos os meios de transportes de massa. Neles é que se tornam visíveis as formas adequadas de comportamento em público (Elias, 1993), como também a relação dos homens e os objetos que informam o status dessa interconexão de local e global; o indivíduo e o mundo. Nesses processos, o que as percepções dessas interações revelam acerca das formas pelas quais se organiza a sociedade? Quais status de seus corpos e de suas coisas parecem ter os sujeitos nos processos de interação social proporcionados pelas tecnologias de transporte? 


\section{Distinções e complexidades da Região Metropolitana do Rio de Janeiro}

6 Minhas indagações se projetam para refletir, por exemplo, sobre as experiências vivenciadas por pessoas como Rute, uma interlocutora que conheci por ocasião de uma pesquisa. ${ }^{2}$ É uma empregada doméstica que trabalha para particulares no município do Rio de Janeiro e que reside em um município distante, na chamada Baixada Fluminense. ${ }^{3}$ Esta mulher, de aproximadamente 40 anos, tem uma relação significativa com o sistema de transportes públicos.

7 Casada e mãe de quatro filhos possui, com seu marido, um modesto imóvel, "mas com quintal e tudo". Para lá se mudou após viver por muitos anos na Favela da Rocinha, localizada na zona sul do Rio. Ela decidiu se mudar do lugar em que nasceu e viveu por 25 anos. Despediu-se dos familiares e dos amigos, muitos dos quais estudaram com ela até o ensino médio. Deixou para trás, entre outras conveniências, oportunidades de trabalho nas imediações de Ipanema, Leblon e São Conrado, bairros estes que abrigam segmentos sociais de maior poder aquisitivo do Rio de Janeiro. E o fez para acompanhar Valdir, um vigilante bancário, com o qual se casou "de véu e grinalda". Juntos decidiram viver em uma localidade distante cerca de $60 \mathrm{~km}$ dali, segundo eles, para terem seu próprio "cantinho".

8 Consequentemente, Rute se desloca todos os dias por dezenas de quilômetros para ganhar a vida como diarista em bairros mais próximos do centro e da zona sul do Rio de Janeiro. Invariavelmente, seus deslocamentos entre estas localidades e a Baixada, envolvendo diferentes meios de transportes, são imprevisíveis. As linhas de ônibus, por exemplo, oferecem serviços caracterizados por unidades lotadas e horários aleatórios e vans, ${ }^{4}$ igualmente abarrotadas, volta e meia enguiçam pelo caminho. Por outro lado, acidentes envolvendo transportes coletivos e/ou particulares são observados com frequência. Com tudo isso, pode ser parte da sua experiência cotidiana enfrentar engarrafamentos intermináveis. A alternativa, sempre, é sair com bastante antecedência de casa. Rute, assim, precisa dedicar um tempo significativo de sua vida à utilização dos transportes públicos, com o objetivo de cumprir a tempo os compromissos com quem a contrata ${ }^{5}$ o que que nem sempre consegue, colocando em risco sua estratégia de contribuir com os gastos da casa. Todo esse conjunto de possibilidades mencionado faz da utilização dos transportes coletivos, como diz ela, uma verdadeira "loteria". Um jogo no qual a doméstica tem que arriscar "cotidianamente".

9 Rute, é claro, constitui apenas um exemplo entre as centenas de milhares de pessoas que subordinam suas estratégias de vida aos sistemas de transportes na Região Metropolitana do Rio. Muitas delas são igualmente moradoras da Baixada, mas há também aquelas que vivem em localidades mais precárias, do ponto de vista da infraestrutura urbana, das zonas norte e oeste do município do Rio de Janeiro. ${ }^{6}$ Muitas dessas pessoas podem viver mais ou menos perto das estações de trens que servem tais localidades, o que faz muita diferença. Aqueles que moram mais próximos dos trens costumam optar por acessar esse modal de transportes. Com isso, concorrem para equacionar o problema dos engarrafamentos. Dificilmente, porém, este fato mitigará questões relacionadas à superlotação e muito menos aquelas de natureza econômica, já que as tarifas são mais caras, ${ }^{7}$ em particular nos horários de maior procura, pela manhã 
e à tarde. Entretanto, tal experiência não é comum a todos que vivem nas diferentes áreas da Região Metropolitana.

10 Na zona sul do Rio de Janeiro, por exemplo, há uma importante oferta de linhas de ônibus, interligando aquela área à parte mais bem equipada da zona norte. ${ }^{8}$ Mais significativo, porém, é que tais linhas de coletivos se combinam com os serviços de trens subterrâneos, conhecidos como "metrô". Estes últimos ligam as zonas sul e norte do município. Ou seja, as linhas disponíveis funcionam apenas dentro da capital do estado e não em outras áreas da Região Metropolitana, como ocorre, por exemplo, em Paris (daí a denominação metro, em francês). Igualmente, parte das linhas de ônibus que ligam as zonas sul e norte do município se conectam também com o Terminal de Barcas na Praça XV. ${ }^{9}$ Segundo minhas observações de campo, o público que pela manhã realiza tal trajeto é predominantemente oriundo dos bairros da zona sul do Rio. ${ }^{10}$ Logo, acessar a localidade de Niterói, considerado o município de melhor Índice de Desenvolvimento Humano (IDH) ${ }^{11}$ da Região Metropolitana, é possível em cerca de 20 minutos para este público.

11 A Baixada, na qual vive Ruth, é significativa para se pensar que o deslocamento espacial e a mobilidade social podem ser representados como desafios, parecendo articulados. Nela, a oferta de transportes públicos é uma forma diferenciada de informar aos habitantes da região sobre a sua pretensa inferioridade (Silva, 2013:62) em relação a outros sujeitos que vivem em áreas distintas da Região Metropolitana. Este é um mecanismo que contribui para reduzir as expectativas de ascensão e mobilidade social de determinados estratos. Lidar com tais situações é um exercício de grande complexidade, tanto para o transcurso da vida cotidiana como também para a análise socioantropológica. Afinal, há todo um conjunto de iniciativas que parecem oscilar entre a utilização de um serviço e a superação de obstáculos sociais. Estas são implicações que parecem derivar de um histórico de escolhas patrocinadas por sucessivas elites políticas.

\section{Entre o deslocamento e a mobilidade}

12 Em termos analíticos, uma primeira coisa a ser feita é separar as esferas de sentido. Separar o que é da ordem do deslocamento e da mobilidade. Assim, Kleiman (2011) faz interessante distinção entre os conceitos de transporte e mobilidade. Segundo o autor, eles guardam interfaces, mas não podem ser entendidos como sinônimos. Os transportes, modais associados aos processos de organização territorial (urbana, metropolitana, regional, nacional e internacional) estão articulados aos processos econômicos e a seus impactos na urbanização, na metropolização, na formação e no desenvolvimento dos fenômenos de periferização e periurbanização. Transportar, porém, é deslocar-se no espaço, o que difere da noção de mobilidade. Os dois, é claro, guardam conexão constante. Para ter mobilidade, necessita-se de transportes. Contudo, não são sinônimos. Transporte como deslocamento cotidiano implica fluxos, ou seja, deslocamentos somente no espaço físico-geográfico, enquanto mobilidade trata dos deslocamentos também no espaço físico-social, implica interações sociais.

Patriota de Moura e Vasconcelos (2012), ao estudarem os processos de mobilidade geográfica e social entre estudantes da Universidade de Brasília, ampliam a compreensão acerca desta distinção. As autoras focalizam a localidade de Ceilândia, uma das chamadas cidades satélites do Distrito Federal, igualmente alvo de estigmas e 
estereótipos. Como ocorre com a Baixada, as reportagens de televisão relatam, por exemplo, as taxas de violência na localidade (Patriota de Moura \& Vasconcelos, 2012:106), que se refletem nos registros da Polícia Civil que computam altas taxas de criminalidade violenta. A população é predominantemente negra e nordestina, reproduzindo o que se pode observar nos municípios da Baixada, no Rio. A pesquisa desenvolvida pelas pesquisadoras também focaliza como um problema importante experiências de deslocamentos de pessoas entre zonas periféricas e centrais.

Dialogando com os trabalhos de Vincent Kauffman, Bergamn e Joye (2006) e também Flamm e Kauffman (2006), as autoras se propõem a recepcionar o conceito de motilidade, proposto pelos mesmos, para pensar a articulação entre mobilidade espacial e mobilidade social. Dão destaque, especialmente, para três dimensões propostas por Flamm e Kaufmann para operacionalização do conceito: acesso, habilidade e apropriação cognitiva. A primeira diz respeito às condições materiais objetivas, ou seja, os modais de transportes e os recursos a eles associados, ${ }^{12}$ nos quais o acesso à mobilidade espacial pode ser observada. A segunda se refere às competências dos sujeitos sociais para transformarem em recursos utilizáveis as possibilidades criadas pela existência do acesso. A terceira dimensão diz respeito à percepção dos sujeitos que, ao se deslocarem de um lugar para o outro, concebem que tais deslocamentos não são operações isentas de complexidade. Pelo contrário, neste transladar adquirem conhecimentos sobre o plano classificatório no qual se engendram desigualdades e estigmatizações, concorrendo para o desenvolvimento de habilidades para instruir seus planos de acesso aos recursos materiais e simbólicos disponíveis na sociedade.

Patriota de Moura e Vasconcelos propõem ainda as noções de trajeto e trajetória para pensar as maneiras pelas quais se podem imbricar mobilidade espacial e mobilidade social nos contextos por elas estudados. A primeira voltada para ponderar sobre a dimensão criativa dos deslocamentos dos sujeitos no espaço urbano; a segunda sintetizada para refletir sobre a maneira pelas quais sujeitos complexos se constituem em movimento, "por meio de processos intersubjetivos e transgeracionais" (2012:89). Como poderá ser visto mais adiante, eu utilizarei a categoria mobilidade articulada em sintonia com tais reflexões.

16 Minhas reflexões também estabelecerão diálogo com as contribuições de José Guilherme Cantor Magnani, o qual recepciona o fenômeno metropolitano a partir de uma perspectiva construída "de perto e de dentro" no que concerne à escala em que se quer olhar para levar a efeito a descrição das relações sociais. Estudando os contextos urbanos, o autor se ocupa de desvendar as relações que tornam a metrópole urbana possível. Assim como Patriota de Moura e Vasconcelos, ele aponta ser este o lugar da heterogeneidade e da diversidade, mas no qual é possível, com um olhar atento que combina perspectivas "macro" e "micro", a descoberta de regularidades nas relações sociais estabelecidas pelos atores. Com o propósito de desconstruir as fragmentações apontadas por outras visões - da imprensa, por exemplo - o antropólogo sugere ser importante construir categorias de análise que auxiliem na mediação entre a apreensão de constructos significativos mais gerais e aqueles compartilhados de maneira mais específica por um determinado grupo social.

Duas delas são particularmente importantes para o presente trabalho: "pedaço" e "circuito". A primeira, captada em suas etnografías sobre relações de vizinhança e problematizada antropologicamente, se refere não apenas a um espaço social, mas sobretudo a uma identidade compartilhada entre pessoas. É construída a partir do 
compartilhamento de certos gostos ou no domínio de certas informações resultantes da sua frequência em determinados lugares. Estes últimos se transformam, assim, num ponto de referência comum, sendo "destacados" do plano físico e projetados nos sujeitos que, desta forma, são parte de e reconhecidos como do "pedaço". Em diálogo com Roberto DaMatta, o autor propõe que entre a casa e a rua existiria um espaço intermediário. Neste se poderia conceber um outro tipo de sociabilidade - entre os "chegados" - organizando planos de interação distintos daqueles em que os registros doméstico (ou familiar) e público (ou impessoal) são predominantes. Já a noção de circuito designa "um uso do espaço e dos equipamentos urbanos - possibilitando, por conseguinte, o exercício da sociabilidade por meio de encontros, comunicação, manejo de códigos". Entretanto, estes se exercem de forma mais independente em relação ao espaço, não se atendo à contiguidade, como ocorre, por exemplo, no "pedaço".

Combinar os argumentos esgrimidos por Patriota de Moura e Vasconcellos, pondo-os em diálogo com os de Magnani, pode resultar em um exercício rentável para minhas reflexões sobre os processos sociais recepcionados em minhas etnografias. Entretanto, outra perspectiva estimulante, que verte sobre o presente trabalho contribuições criativas, é aquela veiculada por Caiafa (2002). A antropóloga realizou etnografías sobre os usos de transportes públicos no Rio de Janeiro e em Nova York, nos EUA, e seus dados me permitem pensar de forma interpolada as questões propostas no presente artigo.

Os contrastes promovidos por Caiafa renderam a caracterização de que a dispersão é a marca da Cidade enquanto forma de organização humana. Neste aspecto, o transporte coletivo tem um papel central. Inspirada em Deleuze, ela propõe que tais modais possibilitam a integração, mas também a "fuga" e, neste diapasão, promovem a mescla de tipos sociais distintos, igualmente dispersos por diferentes "regiões morais". ${ }^{13} \mathrm{~A}$ vida urbana, assim, se caracteriza pela diversidade e pela complexa e progressiva divisão do trabalho e implica, desta maneira, diferentes profissões, formas de entretenimento, padrões de sociabilidade, relações afetivas, entre outros aspectos. A autora chama a atenção para o fato de que, com a Cidade, os espaços geográficos se multiplicam e, com eles, as maneiras de circular. Assim, circular é a maneira primordial de usufruir a vida urbana. A noção de circulação, presente no trabalho da autora - e, como vimos, também nos textos de José Magnani - é de importância capital para os argumentos esgrimidos neste artigo.

\section{Conflitos na contemporaneidade: privatização e processos de gentrificação}

20 Há mais de uma década, Janice Caiafa abordou as implicações da opção da privatização do espaço público vivido nas principais cidades brasileiras. Observou que os transportes coletivos podem ser um dos maiores símbolos do que é público em uma sociedade. Ela o fez contrastando o sistema de transporte do Rio de Janeiro com o de Nova York. Chamou a sua atenção que, ao contrário do restante dos Estados Unidos, as calçadas em Nova York continuaram sendo um lugar importante na trama da Cidade, dotando as localidades de espaços de circulação e encontros. Da mesma forma, não reduziu a existência dos ônibus em favor das autovias para os veículos privados. Pelo contrário, manteve-os, aprimorando sua interseção com outros modais de transportes como, por exemplo, o subway (que, por sinal, também é metro, pois liga a Ilha de Manhattan, em 
Nova York, à cidade de Jersey, no estado de Nova Jersey). E o mais importante: o transporte coletivo é mantido por uma instituição pública, e não privada. É, na perspectiva da autora, um serviço a ser prestado e não essencialmente uma fonte de lucro para as empresas.

21 As decisões políticas que levaram Caiafa a estranhar o processo de privatização do espaço público no Brasil, a partir do exemplo do Rio de Janeiro, experimentam um novo ciclo nos últimos anos. Em especial, no município do Rio de Janeiro, com impactos importantes na Região Metropolitana. Reformulando o município carioca em função de compromissos políticos assumidos com diferentes interesses nacionais e internacionais, o Governo do Estado do Rio de Janeiro e a Prefeitura da Cidade do Rio de Janeiro puseram em prática definições com significativas implicações para a vida das pessoas. ${ }^{14}$ Em virtude de transformar a cidade em uma commodity ${ }^{15}$ capaz de abrigar grandes eventos, a partir de 2008 se iniciou um conjunto de políticas públicas envolvendo as áreas de segurança, transportes públicos e habitação, entre outras.

Estas iniciativas têm tido efeitos e combinações controversos. Os principais dentre eles, em resumo, parecem ter sido as valorizações imobiliárias obtidas em certas regiões do município do Rio de Janeiro, sobretudo após a criação das chamadas UPPs. ${ }^{16}$ Comemoradas em um primeiro momento, tais valorizações foram seguidas de um acelerado processo de substituição dos habitantes de certas áreas: o chamado processo de gentrificação. ${ }^{17}$ Os valores de imóveis para compra e venda, assim como de aluguéis, atingiram patamares inalcançáveis para amplos setores da classe média. ${ }^{18}$ Da mesma forma, o aumento geral do custo de vida parece ter alcançado um nível que guarda identidade com exercícios especulativos de natureza hermética, com índices inflacionários. Muitas famílias tiveram que se mudar dos bairros em que viviam, privando-se da proximidade de suas redes de sociabilidade e de apoio, em busca de lugares mais adequados a seus ingressos financeiros, em geral para lugares de mais difícil acesso, particularmente para aqueles que são dependentes dos meios de transportes públicos (em especial, dos ônibus). Mais numerosos, eles são responsáveis pelo translado de $54 \%$ da população no município carioca, tendo sua infraestrutura bastante criticada. ${ }^{19}$

As políticas supracitadas parecem estar atingindo segmentos da chamada classe média. Isto talvez contribua para compreender a onda de protestos que teve início no Rio de Janeiro em junho de 2013 e que segue seu curso no momento em que escrevo - uma mobilização social que vem envolvendo amplos setores da chamada classe média. Tais protestos, na verdade, emergiram de todo o Brasil quando do início da chamada Copa das Confederações, da FIFA. Entretanto, elas foram mais veementes em termos discursivos e, até aqui, tiveram maior repercussão no Rio de Janeiro, a meu ver em função justamente das dificuldades que se ampliam com a imbricação dos problemas de deslocamento e mobilidade por parte dos setores médios. ${ }^{20}$ Esse é um processo muito recente, o qual declinarei de analisar aqui por ter sobre ele dados etnográficos ainda rarefeitos. 


\section{Transportes públicos e cidadãos: entre Rio de Janeiro e Buenos Aires}

24

Na minha percepção, o surgimento no Brasil de organizações de usuários reclamando melhorias nos transportes públicos é um fenômeno relativamente recente. Um exemplo é a articulação intitulada "Movimento Passe Livre", surgida no Fórum Social Mundial de 2005, com presença em lugares tão díspares como Rio de Janeiro, Belo Horizonte e Brasília. Este é um movimento cujos princípios públicos foram consolidados em julho de 2007, justo quando iniciei minhas pesquisas em Buenos Aires. Assim, na colocação dos meus argumentos, e como referi, eu recorrerei aos dados etnográficos que construí na Região Metropolitana de Buenos Aires entre 2007 e 2009, fazendo contrapontos com aqueles que resultam de minhas etnografias e experiências nos sistemas de transportes no Rio de Janeiro.

Em Buenos Aires eu focalizei, inclusive, possíveis relações entre organizações de usuários de transportes públicos e as instituições responsáveis por tais serviços, em particular em contextos nos quais se manifestavam por melhores serviços, apresentando suas demandas publicamente. Nesta cidade, tais vivências me pareceram aludir a representações de cidadania diversas daquelas que eu observara no Rio.

Nas ações que pude constatar, tinham significativo protagonismo, como vem ocorrendo no Rio, segmentos da chamada classe média. Para defini-la, recorrerei à noção de estratificação social de Max Weber relativa a um fenômeno amplo, que interage mais ou menos fortemente com a desigualdade econômica inerente às sociedades de mercado. A classe média, constituída em função de arranjos sociais específicos, pode ser privilegiada ou oprimida politicamente, além de sofrer maior ou menor discriminação de caráter cultural, dependendo de outras variáveis. Owensby (apud O’Dougherty, 2009) propôs que as identidades de classe média no Brasil haviam sido forjadas historicamente em oposição à classe trabalhadora, particularmente nas distinções em face do trabalho manual, o que articula níveis educacionais diferenciados e práticas de consumo restritas.

O’Dougherty, por sua vez, esgrimindo a proposta de pensar em diacríticos que possibilitassem pensar de forma mais homogênea este fenômeno social, relembra o trabalho de Gilberto Velho (1980), destacando que a mobilidade ascendente da classe média carioca se distinguia pela mudança da zona norte para a zona sul, em especial Copacabana, mudança esta que produzia a ruptura de vínculos (O’Dougherty, 2009:282). Assim, a própria busca de distinção e separação social por parte de um indivíduo ou grupo em relação aos demais é reveladora de um projeto social comum. Será nestes termos que farei referência, tanto no Brasil quanto na Argentina, à identidade social de classe média.

\section{Primeiras aproximações entre Rio e Buenos Aires}

No Rio de Janeiro, município no qual nasci e no qual desenvolvo parte de meu trabalho de campo, foram muitas as viagens que realizei nas linhas de ônibus, como também nos trens da Central do Brasil. Foi neste último, porém, que realizei meu trabalho de natureza etnográfica - transporte utilizado sobretudo pela população de menor poder aquisitivo que reside nas localidades mais distantes, principalmente nos bairros com 
menos infraestrutura pública das zonas norte e oeste do Rio e em localidades análogas da chamada Baixada Fluminense. Construindo etnografias, ouvi pessoas dizerem, muitas vezes satisfeitas, que sua vida se resumia "da casa para o trabalho e do trabalho para casa". Em geral, tais afirmações eram esgrimidas para comentar algum mau sucedido com outros indivíduos, fosse através de notícia pública ou privada. Este tipo de afirmação foi ouvido por mim em outros contextos sociais, inclusive em diferentes meios de transportes públicos. Comumente, veiculavam críticas àqueles que, segundo tais perspectivas, se expunham em demasia no espaço público e eram vitimados por isso.

29 Diga-se a tempo que nas localidades acima referidas também residem pessoas de classe média, ainda que em número mais reduzido do que o que se observa nas áreas mais desenvolvidas das zonas norte e sul do município do Rio de Janeiro. Mas seus deslocamentos, segundo minhas observações, são feitos principalmente em automóveis particulares ou em outras formas de transporte coletivo, por exemplo, nos diversos tipos de ônibus cujas tarifas não se diferenciam pela quilometragem percorrida, como em Buenos Aires, mas pela observância de mais ou menos conforto. Muitos dos que possuem automóveis dizem que com eles se sentem com mais liberdade para circular por distintos espaços, coisa que a utilização de trens e ônibus, e seus recorrentes imprevistos, parece cercear.

30 As expressões e as percepções referidas, se interpretadas a partir de outro prisma, parecem informar limitações territoriais importantes. Limitações, penso, impostas por percepções morais específicas. É possível que a elas interesse uma determinada maneira de organizar a força de trabalho. Em primeiro lugar, para controlar os chamados fatores de produção e, entre eles, o controle do tempo da mão de obra responsável pelo trabalho que, penso, se estende para contextos externos à atividade laboral. Empiricamente constato que quanto maior o tempo de deslocamento de um indivíduo entre a casa e o trabalho, mais desvalorizado tende a ser o contrato que ele pode estabelecer na venda de sua força de trabalho. Há empresas que, ao veicularem propostas de empregos, exigem explicitamente que as pessoas morem próximas do trabalho. Parecem fazê-lo na expectativa de que seus empregados apresentem menor desgaste físico, menor incidência de atrasos ou, possivelmente, para diminuir os encargos derivados dos custos sociais, como o pagamento de auxílio-transporte. Mas parece haver um interesse implícito: controlar o que se consome, em termos culturais e estéticos, na tentativa de se delimitarem possíveis distinções (Bourdieu, 2007). Em outras palavras, as distinções sociais de classe passam também pela territorialização de bens de consumo. Seja como for, as manifestações descritas acima expunham um enquadramento a uma moral dominante. Viver "do trabalho para casa e de casa para o trabalho" não só significa não correr riscos, mas também não se socializar em outros espaços - de formação intelectual, por exemplo - o que poderia permitir mudanças no padrão de vida econômico e cultural, o que contribui para a manutenção da ordem social do "cada macaco no seu galho" (DaMatta, 1997).

31 Voltando aos setores de baixa renda no Rio, é importante dizer que eu tive interlocutores que informavam ter capacidade de circular em diferentes ambientes. Creditavam este fato a certas experiências ou oportunidades a partir de relações pessoais estabelecidas. Embora mais raras, tais conversas remetiam ao reconhecimento de determinadas esferas de circulação que podiam favorecer trajetórias sociais desejadas pelos atores. Em seu somatório geral, tais comentários faziam crer que os 
indivíduos podiam se "perder" ou se "encontrar" nos pretensos "descaminhos" ou caminhos da cidade.

Em Buenos Aires eu observei situações diferentes das descritas acima. Os trens também ligavam a capital argentina aos municípios do chamado conurbano. Em seus deslocamentos eram frequentados por diversas classes sociais. Depreende-se, por um lado, que os segmentos de classe média não só estavam presentes em todo o território da Cidade Autônoma de Buenos Aires, mas também no conurbano. ${ }^{21}$ Por outro lado, tais segmentos sociais mantinham relacionamento estreito com outros, em função da utilização diária dos meios públicos de transportes. Consequentemente, as formas de se comportar publicamente eram comuns, diferente do que observei nos trens da Central, onde vagões de trens eram particularizados para formas distintas de socialização: das festas de aniversário aos cultos religiosos, a sociabilidade era incisivamente popular. Entre a cidade portenha e o conurbano, os comportamentos eram mais homogêneos.

Naqueles contextos, porém, o "imprevisto" ou o "perigo", em termos discursivos, eram representados nos próprios trens. Mais adiante detalharei estas percepções. Tais situações eram denunciadas e criticadas por grupos de usuários, representados amplamente, e que se organizavam para realizar muitas das manifestações políticas que testemunhei durante mais de um ano. Dirigiam suas reclamações públicas às empresas concessionárias e aos governos responsáveis.

Foram estes grupos que eu acompanhei em parte de meu trabalho de campo na cidade portenha e no conurbano bonaerense. ${ }^{22} \mathrm{Eu}$ decidi focalizar, em especial, o sistema ferroviário ao sul, flagrantemente o mais desestruturado, se comparado com aquele que atendia aos municípios ao norte. Mas também fiz incursões ao oeste. Baseado nessa diferença, os agrupamentos de manifestantes denunciavam o governo federal e as empresas por tratamento desigual. No acompanhamento destes agrupamentos, como também nos contatos posteriores com camelôs nos trens e com outros atores, conheci os municípios circunvizinhos à capital.

Também contatei grupos de usuários que reclamavam melhorias para o serviço de metrô, o qual funcionava apenas na Cidade Autônoma de Buenos Aires ${ }^{23}$, enquanto não se apresentavam demandas para os ônibus. Talvez isto possa ser explicado pelo fato de que os ônibus eram (e são) bastante efetivos, existindo dezenas de linhas que se combinam com trens e metrôs. Em seus trajetos, geralmente ligavam um ponto da capital a outro no conurbano. ${ }^{24}$ Mais do que isso, seus percursos circulares, em combinação, faziam com que todas as áreas da capital fossem cobertas, como também várias localidades da Região Metropolitana. Com a configuração quadrangular das ruas e das avenidas e suas numerações padronizadas, a sensação na sua utilização era de grande acessibilidade aos espaços públicos.

Esta me parecia uma diferença fundamental em relação ao Rio de Janeiro, onde as linhas de ônibus faziam (e ainda fazem) roteiros quase que em linha reta, em um município de geografia imprecisa. Dessa forma, os usuários são praticamente obrigados a fazer combinações com outras linhas ou, quando é possível, com outros meios de transportes para chegarem à maioria dos lugares. Além disso, a exemplo do que ocorria com trens e metrôs, as passagens em Buenos Aires eram subsidiadas pelo Estado argentino. Assim, as pessoas, ideal e indiscriminadamente, podiam chegar a qualquer ponto da Grande Buenos Aires com tarifas módicas..$^{25}$ Logo, o que se buscava nos trens $\mathrm{e}$ metrôs era aperfeiçoamento tecnológico, que reduzisse os tempos de viagem, trazendo mais conforto e maior segurança. 
37 A abordagem de tais situações etnográficas, rememoradas em função de experiências mais recentes, me leva a considerar a disposição dos serviços de transportes públicos como expressão de lógicas mais ou menos inclusivas. Consequentemente, o público usuário pode ser representado de forma mais ou menos simétrica, ou submetida hierarquicamente aos formuladores das políticas públicas de transportes. As opções políticas neste sentido acabam por organizar a Cidade ao longo de um determinado período histórico, sendo capazes de informar as características das relações entre os diferentes segmentos, representações estas que incidem sobre as possibilidades de maior ou menor mobilidade dos distintos grupos sociais. São formas que podem sofrer inflexões, embora, abordadas de uma perspectiva de maior alcance, expressem uma certa recorrência na experiência citadina. Por tudo isso, não é o mesmo falar da orquestração de circuitos a partir dos transportes públicos no Rio de Janeiro e em Buenos Aires, considerando as imagens socialmente produzidas de tais serviços em cada lugar e, por conseguinte, os públicos que os utilizam.

\section{Rio e Buenos Aires: algumas distinções importantes}

38 A Cidade Autônoma de Buenos Aires é a sede da capital federal argentina. Buenos Aires também dá nome à maior província daquele país. São dois espaços instituídos política $\mathrm{e}$ juridicamente de formas distintas. Constituem-se, igualmente, enquanto duas regiões culturalmente diferenciadas. Tais distinções não inviabilizavam, porém, minha percepção sobre um possível continuum entre a Cidade de Buenos Aires e parte significativa da Província, com a qual formava a Região Metropolitana. Durante meu trabalho de campo, tal continuidade me pareceu poder ser explicada pela partilha de determinados valores morais e estéticos que referenciavam o cotidiano das pessoas na chamada Gran Buenos Aires.

39 A Cidade de Buenos Aires pode ser representada como um conjunto de ruas e avenidas que, de tempo em tempo, é interrompido por uma estação, uma passagem de nível ou por viadutos que suspendem trilhos sobre uma rua. As linhas férreas impõem descontinuidades às ruas e às avenidas, obrigando muitas vezes as pessoas, sejam pedestres ou motoristas, a aguardarem a passagem das composições para seguirem seus cursos. Os serviços de trens ferroviários, ainda que privatizados, são a representação do poder nacional, já que a privatização é concessão federal. ${ }^{26}$ As demandas por melhores serviços, como referi, envolviam então empresários e representantes do governo nacional. As tramas e as representações do privado e do público se combinavam nos dramas ditados, por assim dizer, pela arquitetura ferroviária. Indivíduos e nação, cotidianamente, experimentavam o conflito.

40 Ao mesmo tempo, a capital federal argentina, como é comum às sociedades de sistema de mercado, é constituída por áreas desiguais em termos de sua organização econômica. Há áreas que concentram pontos turísticos; áreas comerciais que atendem aos consumidores mais exigentes, ou mesmo, em áreas limítrofes, a estabelecimentos industriais. O mesmo se observa, por exemplo, no Rio de Janeiro. Entretanto, eu percebia na cidade portenha uma estrutura mais homogênea em seu conjunto. Os serviços privados, por exemplo, suprem demandas por consumo de públicos diversos restaurantes, armazéns, farmácias, supermercados, verdulerías, entre outros - como também existe uma estrutura pública de escolas, creches e alternativas de entretenimento razoavelmente distribuídas. $\mathrm{O}$ contraste com o Rio me parecia gritante. 
41 No município carioca a distribuição de tais serviços, tanto públicos quanto privados, é mais desigual. Como referi, os bairros da zona sul são mais bem aquinhoados em todos os níveis: das melhores escolas públicas e postos de saúde até, sobretudo, a oferta de bens culturais e de consumo (e, claro, uma maior articulação do sistema de transporte público). São neles que estão as maiores quantidades de cinemas, teatros, museus, centros culturais, entre outras fontes de entretenimento. ${ }^{27}$ Ter acesso a tais serviços para os moradores de outras regiões do município ou da Região Metropolitana, em especial nos finais de semana, esbarra num precário serviço de transportes, a preços elevados. Logo, a maioria das famílias de baixa renda tem uma relação com a cidade praticamente "da casa para o trabalho, do trabalho para casa".

\section{Regiões metropolitanas em perspectiva}

O conurbano bonarense pode ser descrito como constituído de municípios com algumas características em comum. ${ }^{28} \mathrm{Em}$ minhas observações, eles têm como ponto referencial uma praça, em volta da qual se localizavam a Intendência, a Camara de Consejales, ${ }^{29}$ uma igreja e uma escola. Próxima a este conjunto, se localiza a estação de trens, com estacionamentos para carros e bicicletas. A partir deste ponto se dispersavam as casas, as lojas, os supermercados, as verdulerías, os açougues, entre outros estabelecimentos que preenchem os quadriláteros planos que caracterizam a Grande Buenos Aires. Nessa dispersão, em uma significativa quantidade de municípios ao norte, a oeste e ao sul, foram construídos espaços que abrigam diferentes estratos sociais, com seus interesses de consumo: dos restaurantes aos cinemas, das parrillas ${ }^{30}$ de bairro aos pequenos teatros.

43 As estações de trens, próximas às referidas praças, são responsáveis pela circulação de dezenas de milhares de pessoas entre estas localidades e a capital, movimento este responsável, entre 2007 e 2009, por levar aos domínios do Distrito Federal aproximadamente 2 milhões de pessoas cotidianamente. Tal fluxo se desenvolvia a partir das primeiras horas da manhã, tendo no final da tarde seu contrafluxo. Neste, se fazia reescoarem pelas cidades as pessoas. Tal processo, na minha perspectiva, era o que levava ideias, gostos, mercadorias e sonhos a circularem pela capital, onde estão porto, o aeroporto e a rodoviária, instituições que ligam todo mundo ao mundo e o mundo a Buenos Aires e adjacências.

44 Minha compreensão sobre a Grande Buenos Aires tem, portanto, a capital federal argentina como referência na integração com as demais áreas da Região Metropolitana através do sistema de transportes - principalmente os transportes ferroviários, responsáveis naquele período por promoverem o deslocamento do maior contingente de pessoas. No movimento cotidiano entre a capital e o conurbano, me foi possível conceber o compartilhamento de propósitos que davam sentido àquele ir e vir. Sentidos que se estruturavam nas cidades que compunham aquela região na qual vivem cerca de 13 milhões de pessoas. Resumidamente, tais valores envolviam o interesse pela aquisição patrimonial de uma casa própria, enquanto expressão de um direito, como também a aquisição bens culturais, simbolizados pelo acesso à educação superior.

Assim, as pessoas poderiam optar por viver longe da capital, se isto facilitasse a aquisição de um imóvel. Foi o caso, por exemplo, de Margô, mãe de Victor, meu principal interlocutor durante o trabalho de campo. Vendedor ambulante de nacionalidade uruguaia, ele vivia num bairro pobre na localidade de Glew. Sua mãe 
comprou uma casa em rua de terra e sem esgoto, com os recursos de aposentada de um banco uruguaio. Os preços resultantes da partilha do solo eram mais acessíveis nas regiões mais distantes. Esses proprietários reivindicavam continuamente uma melhor estrutura pública de serviços, principalmente na área educacional. Durante o trabalho de campo, eu conheci uma significativa rede de creches e escolas municipais, estabelecimentos educacionais mantidos também pelo governo da Província, e uma crescente rede de universidades nacionais. Atendiam a diferentes áreas da região metropolitana. Como me dizia Victor, tais serviços não nasceram da noite para o dia. Foram fruto de muitas reivindicações, havendo bastante a fazer para melhorá-los em sua infraestrutura. Em outras palavras, havia a permanente demanda por reproduzir no conurbano, tanto quanto possível, o grau de assistência disponível aos habitantes da capital. $\mathrm{O}$ que não quer dizer que isto seria atendido plenamente, ou mesmo em parte significativa. Contudo, o mais importante é que não se aceitava naturalmente a discriminação.

Na minha percepção, a Região Metropolitana do Rio de Janeiro não se apresenta como um todo integrado. As pessoas, como no caso de Rute, que mencionei no início deste artigo, também buscam adquirir propriedades em localidades mais distantes, o que nem sempre é fácil. Ao fazê-lo, testemunham que as oposições entre o município do Rio de Janeiro e aqueles localizados em seu entorno são de distintas ordens e correspondem a lógicas construídas historicamente. Como referi, no interior do próprio município carioca é considerável a desigualdade de serviços públicos e de oferta de bens culturais entre suas zonas sul, norte e oeste. Silva (2013) também chama a atenção para tais aspectos diferenciadores no escopo de desvalorização territorial relacional existente entre os "bairros-subúrbios próximos do centro e da zona sul" do Rio.

Este padrão de desigualdade, segundo o autor, se agudiza para as regiões da chamada Baixada Fluminense, onde o processo de constituição do sistema ferroviário teve um papel importante desde seus primórdios. ${ }^{31} \mathrm{O}$ ponto do autor, com o qual concordo, é que a desigualdade se ampliou com o predomínio dos modais estruturados a partir das construções de uma quantidade importante de rodovias, fazendo com que ocorressem processos diferenciados de valorizações, desvalorizações e revalorizações de distintos territórios e, em função desses processos, das identidades construídas nestes locais. Até hoje os municípios da Região Metropolitana do Rio de Janeiro, particularmente os da Baixada, são chamados de "cidades-dormitório".

\section{A demanda por melhoria dos transportes públicos em Buenos Aires: atores sociais e tecnologias de protesto}

Um dado significativo é que, a partir dos terminais ferroviários de Buenos Aires, eu pude compreender que determinados valores morais partilhados por diferentes segmentos sociais embarcavam nas plataformas e tomavam assento no interior dos trens e, dessa forma, eram assimilados para além da capital, particularmente através das linhas férreas. Contribuíam, assim, para que, em diferentes localidades da Região Metropolitana, os sujeitos de distintas classes socioeconômicas se vissem como iguais em direitos: direito ao trabalho, à educação, à saúde ou, como diziam, a um "tratamento digno", de cidadãos. Utilizando os trens, muitas pessoas iam à capital para se manifestar politicamente por essas demandas. Natural, portanto, que o próprio sistema 
de transportes ferroviários - assim como o metrô - fosse objeto de reivindicações por melhorias.

Havia, por exemplo, grupos de passageiros organizados que reclamavam melhorias nos serviços de trens, que transportavam, na época de minha pesquisa, cerca de 2 milhões de pessoas. As empresas reunidas destinavam ao público serviços caracterizados por atrasos significativos nos horários, composições consideradas em mau estado e mesmo perigosas pelos usuários. ${ }^{32} \mathrm{Na}$ linha General Roca, onde realizei trabalho de campo sistemático, estas ocorrências eram mais frequentes e dramáticas. A opinião dos passageiros organizados, de deputados de partidos de oposição ao governo, ou mesmo de outras autoridades políticas era de que isso ocorria pela falta de investimento das empresas concessionárias na manutenção e na melhoria dos serviços.

Foi por conta desse drama cotidiano que se constituiu o grupamento Pasajeros del Roca, ao qual me integrei em 2007. Tratava-se de um grupo de passageiros de trens que viviam em localidades distintas, em áreas de maior ou menor urbanização ao sul/ sudeste do conurbano, se comparadas com a capital. Eles coordenavam suas atividades a partir de uma lista de discussão na internet com quase 300 pessoas, da qual fiz parte. Nela, os assuntos, volta e meia, redundavam em polêmicas entre distintas visões políticas.

51 Atento aos blogs e, em seguida, participando das listas de discussões que o grupo mantinha na internet, introduzi-me nos temas relacionados ao transporte ferroviário. Pude perceber que tais grupamentos eram formados por pessoas de distintas idades $\mathrm{e}$ posições sociais. Reuniam estudantes universitários, aposentados, trabalhadores das próprias empresas ferroviárias, funcionários públicos, pequenos e médios empresários, donas de casa, desempregados, pequenos comerciantes, entre outros atores. De modo geral, pelos recursos de que dispunham e, sobretudo, pela forma como articulavam conhecimento formal e informação, eu os classificava como classe média, nos termos adotados neste artigo.

52 Mas isto não quer dizer que todos tivessem esse perfil. Eu conheci, por exemplo, um grupo de pessoas que viviam mais modestamente e constituíam um grupamento de pais de adolescentes mortos em acidentes de trens. Eles viviam na localidade de Claypole uma das áreas mais precárias do conurbano - e passaram a integrar os Pasajeros del Roca por meu intermédio, tendo eu os apresentado aos demais. À medida que fui me tornando mais íntimo daquelas pessoas, passei a frequentar suas casas em distintos lugares. Desta forma, pude transformar virtuais contatos em relações de confiança, relações estas que me ensinaram muitas coisas sobre os trens e sobre a sociedade argentina.

53 Ora, nas minhas andanças por Buenos Aires e por localidades do conurbano, em contato com diferentes segmentos sociais, percebi que as avaliações políticas sobre o passado recente argentino coincidiam. Também eram equânimes as análises sobre os efeitos do chamado terrorismo de Estado argentino. As variações das opiniões políticas, em torno de uma maior afinidade com ideais peronistas, radicais, comunistas, socialistas, humanistas ou o que fosse, não tergiversavam sobre o conteúdo autoritário, conservador e de exceção dos governos militares a partir de março de 1976. A virulência de tais governos deixou como legado para o país uma legião de mortos que, no dia a dia da sociedade argentina, me parecia estar presente e ativa. Consequentemente, pude observar manifestações de inconformidade ou mesmo 
desconfiança em relação aos governos e às representações do Estado, em diferenciados níveis de expressão.

\section{Algumas reflexões em perspectiva comparada}

54 Aquelas situações me fizeram pensar que os contrapontos entre as duas regiões metropolitanas nas quais realizei etnografias podem se referir a processos históricopolíticos específicos. Neles, ideias e conceitos, tais como república, igualdade, mercado, entre outros, diferem significativamente (Pires, 2011). São processos que fazem com que estas regiões tenham vocações políticas e econômicas distintas. ${ }^{33} \mathrm{Em}$ todo caso, em ambas as localidades, os ideais liberais são proclamados como estruturantes das relações sociais, econômicas e políticas. Nas maneiras diferenciadas com que se orquestram seus enunciados, me pareceu fundamentarem-se seus sistemas de transportes e suas relações em ideias de mobilidade.

Minhas reflexões, com base nas etnografias que amparam os contrapontos aqui exercitados, ainda que devotadas a analisar configurações citadinas particulares, tendem a se pautar em algumas premissas. A primeira, como referi, é considerar a sugestão de Castells (2012), para quem a experiência urbana contemporânea - que chamo, portanto, de cidade - se constitui no que ele denomina de Região Metropolitana, um território onde o exercício dos mandatários políticos é expressão permanente do conflito. Baseado nesta ideia, me parece que, abordando os temas relacionados aos transportes públicos, particularmente no contexto ocidental, tratamos do essencial de tais experiências. Uma segunda premissa é que, quando analisamos os serviços de transportes públicos, aludimos, também idealmente, à observância de direitos. 0 direito de ir e vir é o mais óbvio deles. Mas como, afinal, se constitui o ir e vir?

Em relação à noção de direito, julgo haver uma afirmação implícita: a da existência de certa uniformidade identitária dos sujeitos, a concepção de que tais sujeitos são indivíduos, ou seja, indivisíveis e, portanto, diferentes. Individualidade que se projeta idealmente enquanto homogeneidade, a matéria abstrata com a qual o Estado deve interagir e que diz respeito à observância de direitos. Daí a dificuldade em lidar com o subjetivo, que é em si a própria diferença, e que se realiza na afirmação do direito ao seu exercício no espaço público. No que concerne aos transportes públicos, neste pretenso ocidente periférico no qual estão inseridas as regiões metropolitanas referidas, nem sempre as políticas públicas voltadas para a sua organização promovem ambientes onde o tratamento igualitário dos sujeitos pode ser observado. É o caso exemplar, como espero ter demonstrado, do Rio de Janeiro.

Meu objetivo no alinhavo destas premissas é estabelecer referências que contribuam para refletir sobre os processos de experimentação da cidade. Esta última, nestes termos, pode ser pensada idealmente não enquanto um plano, mas antes enquanto um conjunto de circuitos. E neste ponto, combinando minhas etnografias com as de Patriota de Moura e Vasconcelos (2012), e partilhando das ideias das autoras sobre trajetos e trajetórias, e também das de Magnani (2007) e Caiafa (2002), concebo nos transportes públicos a possibilidade de contato com a diferença, com a alteridade, com o não igual. Como propôs Magnani, tais circuitos, ainda em termos ideais, se operacionalizam não em função da interligação de territórios, mas sim pela circulação de territorialidades, isto é, das significações e significados que determinados sujeitos 
sociais compartilham em relação aos lugares onde moram, trabalham ou que simplesmente vivenciam ao passar, no decorrer de um certo período.

58 A cidade, assim, resulta das diferenças que se encontram, se desafiam, se mesclam, impedindo que a cidade se desdobre sobre si mesma, repetindo ciclos. Nestes termos, ela se amplia sempre, resultando dos conflitos inerentes aos processos inacabáveis e imprevisíveis de sua propagação. Neste movimento, papel decisivo pode cumprir o sistema de transportes, como em Buenos Aires, por se opor às noções limitadoras de espaço e tempo que, por ventura, sejam preconcebidas e idealizadas politicamente enquanto regimes de dominação. Tais conflitos se erigem em função da imprevisibilidade de seus circuitos, os quais, uma vez percorridos, podem incluir na perspectiva da cidade aqueles que estão às suas "margens". Desta forma, é possível desconstruir a pretensa marginalidade, desde sempre uma categoria de acusação veiculada por empreendedores morais (Becker, 2008), zelosos guardiões do status quo. Estar à margem passa a ser, assim, mais posição que condição, uma circunstância que se experimenta ou que se consolida em função da capacidade de maior ou menor mobilidade.

59 Em outras palavras, a mobilidade implica não só a possibilidade, mas também a efetividade e a eficácia dos deslocamentos no espaço, permitindo aos sujeitos sociais se encontrarem em âmbitos sociais diferentes. São processos que promovem um possível acesso a uma mudança social, como a passagem de uma classe social para outra representações com as quais estabeleci contato, em maior ou menor grau, nos contextos por mim estudados nas duas sociedades.

60 A mobilidade, assim, se constitui na possibilidade de um sujeito social ultrapassar os obstáculos físicos, morais e estéticos para a realização de seus interesses - mobilidade esta que pode encontrar no sistema de transportes um recurso técnico importante para o estabelecimento de tantos circuitos alternativos quantos sejam possíveis em consequência da existência humana no espaço e no tempo. Mas que pode encontrar também um poderoso símbolo dos limites impostos, por engendramentos políticos, à sua aquisição, em função das desconexas formas de organização dos modais, consumindo tempo e energia na sua utilização urbana e metropolitana. Isto, pela ausência de previsibilidade, que desintegra a relação ótima entre tempo e espaço, sua atribuição, ou pela planilha abusiva de preços, que concorre com outros itens de consumo para inflacionar salários, entre tantas outras variáveis que, mais do que informar ao intelecto racional, fazem com que a população "sinta na carne" suas vicissitudes. Como ocorre com Rute, por exemplo, e parece ocorrer cada vez mais com determinados segmentos da classe média no Rio de Janeiro.

61 A cidade é, ou pelo menos pode ser, um conjunto de circuitos que se amplia e se atualiza em função dos interesses e das estratégias dos sujeitos, que são colocados face a face em virtude, sobretudo, das relações que se efetivam em decorrência desses transportes de pessoas e coisas, na busca para construir mobilidades. A cidade é aquilo que se transporta. O ir e vir dos sujeitos e de seus objetos é, por assim dizer, o Direito que atualiza os circuitos e, portanto, os conflitos.

62 Como território de conflito possui início(s), meio(s) e fim(ns). Exercitemos o jogo de palavra proposto. $\mathrm{O}$ início da cidade não está num eventual pórtico fixado pela autoridade municipal, nem na divisa consensuada com a cidade vizinha. $O$ início está em cada interesse, que pode ter por base uma casa, um banco de praça, a proteção de uma ponte, um grupo familiar, uma manifestação on-line. Este início (ou princípio) é o 
marco a partir do qual se constrói o deslocamento. A meta é o retorno, ou seja, a construção do circuito. Mas este último pode envolver novos marcos, na medida em que os interesses se modifiquem, se diversifiquem. Logo, vir pode ser diferente de voltar.

63 Ir e vir é, assim, um direito em virtude do qual estabelecemos contatos e, concomitantemente, contratos. É quando nos apropriamos cada vez mais do tempo e do espaço, em prol de novos contatos e da diversificação dos contratos. Não significa, neste sentido, ir e vir sempre de um mesmo lugar para outro, igualmente preestabelecido. Não é o destino que importa, mas a maneira como se toma a direção. Não ter o direito de ir e vir assegurado, em decorrência de planificações pretensamente malfeitas, ou planejadamente mal-intencionadas, é uma intromissão nos contratos que podem ser feitos em prol de estratégias e metodologias de mobilidade.

64 O sistema de transportes pode ser não apenas parte das tecnologias da multiplicação das cidades, mas sim uma técnica por excelência pela qual a cidade pode se tornar expressão do poder do público, em detrimento do poder público, enquanto expressão do poder estatal. É no transporte efetivo das pessoas e de suas coisas que os citadinos podem ter acesso a seu fim, qual seja, a destruição do plano, da arquitetura predita, em favor dos circuitos imprevisíveis e aleatórios.

Este fato nos leva a conceber que a previsão que se pode ter do sistema de transportes, por exemplo, é condição para se criar imprevisibilidade, possibilitar trajetórias imaginadas, mas também inimagináveis, permitir o encontro do projeto e do acaso para, enfim, padronizar aquilo que contemporaneamente se concebe como imprevisto, que outra coisa não é senão a prescrição do precário como padrão da existência de milhares. Como no Rio, por exemplo. É através da imprevisibilidade das trajetórias dos sujeitos que se pode, por fim, precarizar a intolerância, fazer com que ela deixe de ser o padrão que informa a discriminação e oblitera a cidadania em sua acepção contemporânea.

\section{BIBLIOGRAFIA}

ALVES, José Claudio Souza. 2003. Dos Barões ao Extermínio: uma história de violência na Baixada Fluminense. Rio de Janeiro. APPH-Clio.

BECKER, Howard S. 2008. Outsiders - Estudos de sociologia do desvio. Rio de Janeiro: Jorge Zahar. BOURDIEU, Pierre. 2007. A distinção. Crítica social do julgamento. Porto Alegre: Zouk.

CAIAFA, Janice. 2002. Jornadas Urbanas: exclusão, trabalho e subjetividade nas viagens de ônibus na cidade do Rio de Janeiro. Rio de Janeiro: Editora FGV.

CASTELLS, M.A. 1983. A questão urbana. Rio de Janeiro: Editora Paz e Terra.

2012. "La cambiante centralidad urbana en las regiones metropolitanas del siglo XXI in Ciudades del 2010". In: Alicia Ziccardi Contigiani (org.). Entre la sociedad del conocimiento y la desigualdad social. Ciudad de México, Distrito Federal: Universidad Nacional Autónoma de México/ Programa Universitario de Estudios sobre la Ciudad, México. 
DAMATTA, Roberto. 1997. Carnavais, Malandros e Heróis: para uma sociologia do dilema brasileiro. Rio de Janeiro: Rocco.

DOSSIÊ COMITÊ POPULAR DA COPA E OLIMPÍADAS DO RIO DE JANEIRO 2011. Megaeventos e Violações de Direitos Humanos no Rio de Janeiro. Rio de Janeiro.

ELIAS, N. 1993. O processo civilizador. Rio de Janeiro: Jorge Zahar.

FLAMM, Michael \& KAUFMANN, Vincent. 2006. "Operationalising the Concept of Motility: A Qualitative Study". Mobilities, 1 (2):167-189.

GROISMAN, F. 2013. “Gran Buenos Aires: Polarización de ingresos, clase media e informalidad laboral, 1974-2010”. Revista Cepal, pp. 85-105.

HALL, P. \& PAIN, K. 1996. “From Metropolis to Polypolis”. In: HALL, P. \& PAIN, K (eds.). The Polycentric Metropolis. Learning from Mega-City Regions in Europe. London: Earthscan. pp. 3-16.

KAUFMAN, Vincent; BERGMAN, Manfred \& JOYE, Dominique. 2004. "Motility: Mobility as Capital". International Journal of Urban and Regional Research, 28(4):745-756.

KLEIMAN, M. 2011. Apontamentos sobre mudanças em mobilidade e transporte na metrópole do Rio de Janeiro. Chão Urbano (Online) 1:19-40.

MAGNANI, J.G.C. 2005. "Os circuitos dos jovens urbanos". Tempo Social - Revista de Sociologia da USP, 17(2):173-205.

MAGNANI, José Guilherme Cantor \& SOUZA, Bruna Mantese de. 2007. Jovens na metrópole: etnografias de circuitos de lazer, encontro e sociabilidade. São Paulo: Terceiro Nome.

NUNES, Edson. 2010. A Revolta das Barcas - Populismo Violência e Conflito Político. Rio de Janeiro: Ed. Garamond.

O'DOUGHERTY, Maureen. 2009. Auto-retratos de clase media: jerarquias, de "cultura" y consumo em São Paulo. In: Sergio E. Visacovsky \& Enrique Garguin (orgs.). Moralidades, Economias e Identidades de Clase Media - Estudios Historicos y Etnograficos. Buenos Aires: Antropofagia.

OWENSBY, Brian. 1994. "Stuck in the Middleo": Middle Class and Class Society in Modern Brazil, 1850-1950. PhD Tesis, Yale University.

PARK, Robert E. 1979. “A cidade: sugestões para a investigação do comportamento humano no meio urbano". In: O.G. Velho (org.). o fenômeno urbano. Rio de Janeiro: Jorge Zahar.

PATRIOTA DE MOURA, Cristina P. 2012. Condomínios no Brasil Central - Expansão Urbana e Antropologia. Brasília: Letras Livros/ Editora UnB.

PATRIOTA DE MOURA \& VASCONCELOS, L.F.L. 2012. “Trajetos, trajetórias e Motilidade na Universidade de Brasília”. Antropolítica: Revista Contemporânea de Antropologia, 32: 87-112.

PIRES, Lênin. 2011. Esculhamba, mas não esculacha! - Uma etnografia sobre os usos urbanos dos trens da Central do Brasil. Niterói, RJ: EdUFF.

2010. Arreglar não é pedir arrego - uma etnografia de processos de administração institucional de conflitos no âmbito da venda ambulante em Buenos Aires e Rio de Janeiro. Tese de Doutorado, Programa de Pós-Graduação em Antropologia, UFF.

SÁNCHEZ GARCIA, Fernanda Ester. 1997. Cidade espetáculo: política, planejamento e city marketing. Curitiba: Palavra. 
SILVA, Jorge. 2005. Violência e identidade social: um estudo comparativo sobre a atuação policial em duas comunidades no Rio de Janeiro. Tese de Doutorado, Programa de Pós-Graduação em Ciências Sociais, Universidade do Estado do Rio de Janeiro.

SILVA, L.A.M. 2010. “Afinal, qual é a das UPPs?”. Disponível em: http:// www.observatoriodasmetropoles.ufrj.br/artigo_machado_UPPs.pdf. Acesso em 14/07/2013.

SILVA, Vinicius Fernandes. 2013. Em pé ou sentado? Um estudo sobre transportes urbanos, mobilidade e identidades territoriais no Rio de Janeiro. Projeto de Tese de Doutorado, Programa de Pós-Graduação em Planejamento Urbano do IPPUR-UFF.

SIMÕES, Manoel Ricardo. 2006. A cidade estilhaçada: restruturação econômica e emancipações municipais na Baixada Fluminense. Tese de Doutorado, Programa de Pós-Graduação em Geografia, UFF.

SMITH, Neil. 1996. The new urban frontiers: gentrification and the revanchist city. London: Routledge.

VELHO, Gilberto. 1980. A Utopia Urbana. Rio de Janeiro: Jorge Zahar.

VIRILIO, Paul. 1996. Velocidade e Politica. São Paulo: Ed. Estação da Liberdade.

\section{NOTAS}

1. No Brasil, o parágrafo $3^{\circ}$ do artigo 25 da Constituição Federal dispõe que cabe aos estados a instituição de Regiões Metropolitanas, nestes termos.

2. Rute e Valdir, seu marido, foram entrevistados no contexto do projeto de pesquisa "As cidades, seus problemas e seus públicos: mobilizações coletivas, territorialidades e políticas públicas de administração institucional de conflitos", Edital Pensa Rio, da Faperj, desenvolvido principalmente por pesquisadores do INCT-InEAC entre 2010 e 2012.

3. A Baixada Fluminense é formada por um conjunto de municípios localizados na Região Metropolitana do Rio de Janeiro. São eles: Duque de Caxias, Nilópolis, Nova Iguaçu, São João de Meriti, Belford Roxo, Magé, Japeri, Guapemirim, Mesquita, Queimados, Itaguaí e Seropédica. Segundo Simões (2006), este é um termo que designa uma ampla região a noroeste do RJ e que, no século XIX, constituía uma zona essencialmente rural. Com o passar dos anos, estas localidades se expandiram, formando municípios que integraram outras áreas mais distantes. Há, porém, a categoria Baixada, que se associa e se descola da representação geográfica referida. Não há acordo conceitual ou semântico sobre o que significa. É mais uma percepção, como propõe Silva (2013), sobre um conjunto de identidades territoriais homogeneizadas, a partir de um ponto de vista construído midiaticamente, associando-as à precariedade da infraestrutura de serviços públicos e a contextos nos quais se observa um alto índice de criminalidade violenta. No presente texto, ao denominar Baixada, estarei aludindo a esta representação. Ver também Alves (2003).

4. Como são conhecidos grandes automóveis, pertencentes a particulares ou a cooperativas de motoristas, que oferecem serviços de transportes sob licenciamento ou não por parte das Prefeituras dos municípios da Região Metropolitana do Rio de Janeiro.

5. Em média, a diarista cobra por seus serviços $\mathrm{R} \$ 80$ (oitenta reais) por dia. Mensalmente, ela costuma receber cerca de $\mathrm{R} \$ 1.760$ (hum mil, setecentos e sessenta reais). Pouco mais que dois salários mínimos e meio, cujo valor, em julho de 2013, é de R\$ 678,00. Fonte: http:// portal.mte.gov.br/sal_min/. Acesso em 13/7/2013.

6. Em localidades como, por exemplo, Oswaldo Cruz, Marechal Hermes, Costa Barros, Magalhães Bastos, entre outras, que seguem os ramais dos trens de forma contígua.

7. No momento em que escrevo este artigo a tarifa básica de ônibus corresponde a $\mathrm{R} \$ 2,75$, enquanto a dos trens urbanos custa $\mathrm{R} \$ 2,90$. 
8. Onde estão, por exemplo, os bairros do Rio Comprido, Tijuca, Grajaú, Andaraí, Vila Isabel, São Cristóvão, Maracanã e, um pouco mais adiante, a localidade do Méier.

9. Localidade próxima às margens da Baía de Guanabara, na qual se proclamou a República do Brasil em 15 de novembro de 1889, daí o nome.

10. Parte significativa constituída de estudantes da Universidade Federal Fluminense, cujos principais campi estão localizados no município de Niterói.

11. O Índice de Desenvolvimento Humano (IDH) é uma medida resumida do progresso a longo prazo em três dimensões básicas do desenvolvimento humano: renda, educação e saúde. 0 objetivo da criação do IDH foi o de oferecer um contraponto a outro indicador muito utilizado, o Produto Interno Bruto (PIB) per capita, que considera apenas a dimensão econômica do desenvolvimento. Segundo a Organização das Nações Unidas, o conceito de desenvolvimento humano nasceu definido como um processo de ampliação das escolhas das pessoas para que elas tenham capacidades e oportunidades para serem aquilo que desejam ser. Ver em http:// www.pnud.org.br/IDH/DH.aspx. Acesso em 06/10/2013.

12. Por exemplo, o ônibus e a existência de um cartão para pagar tarifas mais baratas, ou o trem e o domínio de seu quadro de horários.

13. "Região Moral" é um termo cunhado por Robert Ezra Park, expoente da Escola de Chicago, para definir uma região da cidade cujos habitantes, que não residem necessariamente aí, mas apenas deambulam pela zona, "tendem a segregar-se, não apenas segundo seus interesses, mas ainda segundo seus gostos e temperamentos" (Park, 1979).

14. Com o advento de grandes acontecimentos no Rio de Janeiro, um conjunto de obras propõe novas maneiras de transportar, ainda que privilegiando o modal automotor. A maior parte dos gastos se destina à construção dos chamados BRTs (Bus Rapid Transit) e BRSs (Bus Rapid System), destinados aos públicos mais pobres da zona oeste, enquanto a ampliação do metrô só ocorre na zona sul. Segundo a Prefeitura, a decisão se deve à urgência em atender à maioria da população (Ver Revista Carta Capital, n. 752, p. 23, 12/6/2013). Entretanto, levantamentos realizados por órgãos da grande imprensa demonstram que as empresas de ônibus, monopólio de poucas famílias, figuram entre as principais financiadoras das campanhas políticas do prefeito e do governador. Ver Dossiê Comitê Popular da Copa e Olimpíadas do Rio de Janeiro, 2011.

15. Uma cidade como commodity corresponde a um território de consumo, no qual a própria cidade parece se transformar em mercadoria a ser consumida. Ver, por exemplo, Sánchez Garcia (1997).

16. A Unidade de Polícia Pacificadora (UPP) é uma política pública do governo do estado do Rio de Janeiro, que propôs, em um primeiro momento, a ocupação militar de algumas favelas cariocas para possibilitar o controle territorial das mesmas por parte da polícia, deslocando grupos que se dedicavam à venda no varejo de drogas ilícitas. Sobre elas ver Machado da Silva (2010).

17. Derivado do inglês "gentry", que significa pequena aristocracia, a expressão da língua inglesa gentrification foi usada pela primeira vez pela socióloga britânica Ruth Glass, em 1964, ao analisar as transformações imobiliárias em determinados distritos londrinos. Neil Smith, entretanto, no ensaio The new urban frontiers: gentrification and the revanchist city (1996), analisa o processo em profundidade, consolidando-o como conceito acerca de um fenômeno social contemporâneo. 0 termo se refere, em geral, à recapitalização de espaços urbanos residenciais e de comércio independentes, com novos empreendimentos prediais e de grande comércio, ou seja, a substituição de pequenas lojas e residências por edifícios residenciais e comerciais de alto padrão. O resultado é a valorização imobiliária desses espaços. Tais iniciativas são acompanhadas de substituição da população de áreas das grandes metrópoles, tradicionalmente ocupadas por segmentos sociais subalternos, com o consequente deslocamento dessas populações.

18. Mais adiante veicularei a definição de classe média utilizada no presente artigo.

19. Segundo o Consórcio das Empresas de Ônibus do Rio de Janeiro, o Rio-Ônibus, em 2012 havia cerca de 8.700 ônibus, os quais transportavam aproximadamente 100 milhões de passageiros/ 
mês. Ver http://www.rioonibus.com/rioonibus-wordpress/wp-content/uploads/2013/07/TB4Resumo+do+sistema+de+ transporte+por+onibus+no+municipio+do+Rio+de+Janeiro++1984+a+2012_20130605.pdf. Acesso em 04/10/2013). Pesquisa realizada de maio a junho de 2013 pela Empresa M. Sense, com 1.521 moradores do município, demonstrou que, dos modais disponíveis na cidade (incluindo automóveis particulares), o ônibus é o mais utilizado (por 54\% dos cariocas) e recebeu a pior avaliação: $50 \%$ dos entrevistados deram notas bem baixas, até quatro. Ver http://www.mobilize. org. br/noticias/4471/frota-de-onibus-no-rio-edesproporcional-ao-numero-de-passageiros.html. Acesso em 04/10/2013.

20. As mobilizações iniciadas em junho - apelidadas de "revolução dos vinte centavos" - tiveram como desencadeador o aumento da ordem de vinte centavos nas tarifas de transportes públicos em diferentes cidades. Processo muito complexo, ele se deu simultaneamente ao início da Copa das Confederações da Federação Internacional de Futebol - FIFA. É possível que a revolta tenha se nutrido das sucessivas denúncias de superfaturamento na construção dos estádios de futebol (as chamadas Arenas FIFA), as quais contaram com subsídios dos governos federal, estaduais e municipais. Em meados de outubro de 2013, muito embora as mobilizações tenham arrefecido na maioria do país, elas seguem radicalizadas no Rio de Janeiro, a tal ponto que se têm pautado debates como o da desmilitarização da Polícia Militar, que vem atuando de maneira progressivamente violenta. Da mesma forma, a lei que define crime organizado foi alterada em agosto último, permitindo que jovens sejam enquadrados no crime de formação de quadrilha por conta das insistentes manifestações no Rio e, em alguns casos, em São Paulo.

21. Groisman (2013), analisando o processo econômico argentino, registra o crescimento da chamada classe média. Segundo ele, no período entre 2003-2010, na região da Grande Buenos Aires - na qual se concentram 30\% da população da Argentina - políticas públicas de distribuição de renda possibilitaram às classes médias e baixas perceberem maiores ingressos financeiros, fazendo com que $8 \%$ da população se incorporassem à classe média. De acordo com Groisman, isto se deveu tanto a um processo de mobilização social ascendente como também a uma contração de segmentos das classes mais altas.

22. Em Buenos Aires, além de Constitución, havia outros cinco terminais de trens pelos quais circulavam cerca de 1 milhão e meio de pessoas todos os dias. Cada uma das seis linhas de trens apresentava características bem peculiares, ainda que todas funcionassem a partir da administração de empresas privadas. A exemplo do que ocorreu no Rio de Janeiro, na década de 1990, todas foram privatizadas. Diferentemente do Rio, onde apenas uma concessionária privada era responsável pela prestação dos serviços, em Buenos Aires havia quatro empresas responsáveis pela administração dos transportes ferroviários.

23. Num total de cinco linhas, na época de minha pesquisa, o serviço de metrô, que funcionava das $6 \mathrm{~h}$ às $23 \mathrm{~h}$, atendia a todas as regiões da cidade, sendo que a maioria de suas estações terminais se combinava com terminais de ônibus e trens.

24. Em Buenos Aires há pelo menos 137 linhas de ônibus, a maioria das quais liga a capital federal a diferentes partes do chamado conurbano, inclusive algumas localidades que não constituem a Região Metropolitana. Ver http://www.xcolectivo.com.ar/colectivo/. Acesso em 13/7/2013.

25. Naquele período, uma passagem custava em média 0,70 (setenta centavos de peso). Em comparação com o dólar, isso representava aproximadamente US\$ 0,25. No Brasil, no mesmo período, as passagens custavam, também em comparação com o dólar, cerca de quatro vezes mais. Ver Pires (2010).

26. No Rio de Janeiro a concessão é estadual, já que antes da privatização o governo federal repassou o controle das ferrovias para o estado.

27. Muitas vezes oferecidos de forma gratuita como iniciativa, por exemplo, da Prefeitura Municipal do Rio de Janeiro.

28. Definida pelo decreto-lei 70/1948, é atualmente formada por 24 cidades, além de Buenos Aires. 
29. Similar à Prefeitura e à Câmara de Vereadores, respectivamente.

30. Espécie de restaurante especializado em carne na brasa.

31. A partir dela, na segunda metade do século XIX, a produção do café pôde ser escoado do Vale do Paraíba para os portos do Rio. Com isso, as terras da cidade puderam ser destinadas a outras formas de produção e ocupação. Com a crescente produção de café, e os processos internacionais favoráveis, observou-se significativa acumulação de capital por parte das elites naquele período, basicamente comerciantes responsáveis pela exportação-importação e banqueiros. Tal acumulação iria favorecer o processo de industrialização subsequente, tendo como lugar privilegiado a cidade do Rio, "enfraquecendo os vínculos com sua periferia imediata, que se transforma em local de passagem" (Simões, 2006:70).

32. Segundo levantamentos que fiz, observando registros de ocorrências nos chamados libros de quejas disponibilizados pela empresa UGOFE, destinados aos passageiros.

33. Na Grande Buenos Aires está a maior concentração demográfica da Argentina. A população economicamente ativa desenvolve atividades ligadas ao insipiente parque industrial, mesmo após a chamada crise de 2001. No Rio, diferentemente, as atividades ligadas ao setor de serviços é o que costuma empregar a maioria da população economicamente ativa.

\section{RESUMOS}

O artigo propõe uma reflexão sobre possíveis percepções a respeito da utilização de transportes públicos e representações de cidadania. A abordagem utiliza dados construídos em etnografias realizadas nas Regiões Metropolitanas de Buenos Aires, na Argentina, e Rio de Janeiro, no Brasil. Ao utilizarem os serviços de transportes, os atores sociais, em uma dada sociedade, parecem relacionar dimensões de espaço e tempo, construindo e/ou conjugando formas específicas de classificação dos espaços sociais compartilhados na Região Metropolitana. 0 artigo explora as noções de mobilidade, circuito, trajetória, entre outros, com o intuito de sinalizar para as possíveis vinculações entre previsibilidade no exercício de direitos e imprevisibilidade das trajetórias sociais.

In this article I propose to reflect about the use of public transportation and representations of citizenship. My approach will seek to use data constructed in ethnographies in the metropolitan areas of Buenos Aires, Argentina, and Rio de Janeiro, Brazil. Using public transportation social actors at an specific society seem to relate dimensions of space and time, constituting specific classificatory forms of space shared in the metropolitan area. The article explores the notions of mobility, circuit, trajectory, among others related to the urban anthropology, in order to signal the possible linkages between predictability in the exercise of rights and unpredictability of social trajectories.

\section{ÍNDICE}

Keywords: public transportation, conflict, citizenship, mobility

Palavras-chave: transporte público, conflito, cidadania, mobilidade 


\section{AUTOR}

\section{LÊNIN PIRES}

UFF INCT-InEAC Lênin Pires é doutor em Antropologia pelo Programa de Pós-Graduação em Antropologia da Universidade Federal Fluminense (PPGA/UFF). Professor Adjunto do Departamento de Segurança Pública da Faculdade de Direito da UFF. É Pesquisador Associado ao Instituto Nacional de Estudos Comparados em Administração Institucional de Conflitos (INCTINEAC), também sediado na Universidade Federal Fluminense. Tem experiência em etnografias de Processos de Administração Institucional de Conflitos, focalizando as dinâmicas de expansão urbana e suas relações com os mercados metropolitanos de economia popular, analisando as relações entre conflito, direito e segurança pública. Contato: leninpires@id.uff.br 